\title{
Delaying childbearing: effect of age on fecundity and outcome of pregnancy
}

\author{
Boukje M van Noord-Zaadstra, Caspar W N Looman, Hans Alsbach, J Dik F Habbema, \\ Egbert R te Velde, Jan Karbaat
}

\begin{abstract}
Objectives - To study the age of the start of the fall (critical age) in fecundity; the probability of a pregnancy leading to a healthy baby taking into account the age of the woman; and, combining these results, to determine the age dependent probability of getting
\end{abstract} a healthy baby.

Design-Cohort study of all women who had entered a donor insemination programme.

Setting-Two fertility clinics serving a large part of The Netherlands.

Subjects-Of 1637 women attending for artificial insemination 751 fulfilled the selection criteria, being married to an azoospermic husband and nulliparous and never having received donor insemination before.

Main outcome measures-The number of cycles

Toeqepast

Natuurwetenschappelijk

Onderzoek Institute of

Preventive Health Care, Child Health Division,

PO Box 124, 2300

AC Leiden,

The Netherlands

Boukje $M$ van Noord-

Zaadstra, MSC, epidemiologist

Department of Public

Health and Social

Medicine, Erasmus

University Medical School,

Rotterdam, The

Netherlands

Caspar W N Looman, MSC, statistician

J Dik F Habbema, PHD, professor of medical decision sciences

Department of Obstetrics and Gynaecology, University Hospital, Utrecht, The Netherlands Hans Alsbach, MSC, medical data manager Egbert R te Velde, MD, professor of reproductive medicine

\section{Cryo Biological}

Laboratories, Bijdorp,

Barendrecht,

The Netherlands

Jan Karbaat, MD, medical director

Correspondence to: Mrs van Noord-Zaadstra.

BMf 1991;302:1361-5 before pregnancy (a positive pregnancy test result) or stopping treatment; and result of the pregnancy (successful outcome).

Results - Of the 751 women, 555 became pregnant and $\mathbf{4 6 1}$ had healthy babies. The fall in fecundity was estimated to start at around 31 years (critical age); after 12 cycles the probability of pregnancy in a woman aged $>31$ was 0.54 compared with 0.74 in a woman aged 20-31. After 24 cycles this difference had decreased (probability of conception 0.75 in women $>31$ and 0.85 in women 20-31). The probability of having a healthy baby also decreased - by $3.5 \%$ a year after the age of 30 . Combining both these age effects, the chance of a woman aged 35 having a healthy baby was about half that of a woman aged 25 .

Conclusion-After the age of 31 the probability of conception falls rapidly, but this can be partly compensated for by continuing insemination for more cycles. In addition, the probability of an adverse pregnancy outcome starts to increase at about the same age.

\section{Introduction}

Female fecundity (the ability to conceive) is generally acknowledged to decrease with increasing age, but the beginning of the fall in fecundity has not been pinpointed to a specific age. Such information is of importance to the increasing number of women who are delaying childbearing. In naturally selected populations studying the decrease in fecundity caused by biological factors is confounded by diminished sexual activity with age and possibly also by a decrease in male fertility. Schwartz and Mayaux studied the age effect in women treated by artificial donor insemination. Their data suggest that reduced fecundity starts around the age range 31-35, but their follow up time of 12 cycles was relatively short. Older women who continue treatment for a much longer period may eventually conceive. ${ }^{2}$ Moreover there is evidence that advancing maternal age has an adverse effect on the outcome of pregnancy because of a higher abortion and perinatal mortality. ${ }^{3}$

Our study of a cohort of women receiving donor insemination was undertaken to examine the age of the start of the fall in fecundity (critical age), the probability of a pregnancy leading to a healthy baby taking into account the age of the woman, and the age dependent probability of getting a healthy baby, by combining the critical age and the probability of a pregnancy leading to a healthy baby.

\section{Subjects and methods}

Two fertility clinics (A and B) serving different geographic areas participated in the study. Women were referred to the clinics by a general practitioner or a specialist. The source population consisted of all women who attended the clinics for artificial donor insemination between January 1973 and the years when the protocols were changed from treatment with fresh semen to frozen semen (1980 for clinic A and 1986 for clinic B).

A total of 1637 women entered the artificial insemination programme in the two clinics, 1036 in clinic $\mathrm{A}$ and 601 in clinic B. We studied the 751 women, 444 from clinic A and 239 from clinic $B$, who satisfied the selection criteria - that is, women who were married to an azoospermic husband, were nulliparous, and had never received artificial insemination before.

Insemination procedures were usually conducted in every subsequent menstrual cycle. Women were inseminated intracervically, and timing of insemination was estimated on the basis of the basal body temperature chart and by judging the quality of cervical mucus. On average the number of inseminations per cycle was three for clinic A and two for clinic B. Fresh semen was used from donors aged 25-45 with a proved fertility (having fathered at least one child) and with sperm properties satisfying the World Health Organisation criteria.

In clinic $A$ the specialists were free to prescribe supplementary treatment such as induction of ovulation by clomiphene if a woman did not conceive after a few cycles. In clinic $B$ induction of ovulation was largely confined to women who proved to have anovulatory cycles or who had very long cycles during an observation period before treatment. If induction of ovulation was started the treatment was continued in subsequent insemination cycles. If a woman did not conceive hysterosalpingography was performed after the sixth cycle and laparoscopy after the twelfth cycle.

All women were followed until the end of treatment with artificial insemination. The end was defined as the result of each woman's last insemination cycle, being either a confirmed pregnancy (success) or stopping treatment without pregnancy (failure). Only first con- 


\begin{tabular}{lcc}
\hline $\begin{array}{l}\text { Age } \\
\text { years) }\end{array}$ & $\begin{array}{c}\text { No of } \\
\text { women }\end{array}$ & $\begin{array}{c}\text { No(\%)who } \\
\text { became } \\
\text { pregnant }\end{array}$ \\
\hline $18-24$ & 111 & $86(78)$ \\
$25-29$ & 390 & $298(76)$ \\
$30-34$ & 201 & $146(75)$ \\
$35-42$ & 49 & $25(51)$ \\
\hline Total & 751 & $555(74)$
\end{tabular}

ceptions as a result of the artificial insemination were used for the analysis. Fifteen women who did not report the results of their last insemination cycle were recorded as a failure up to their last but one cycle.

If menstruation did not start after two weeks the women were instructed to contact the clinic for a pregnancy test. If the test result was positive the woman was assumed to be pregnant and was referred to her family doctor. Women were asked to report the outcome of pregnancy. Successful pregnancy was defined as a pregnancy leading to the birth of a healthy child.

\section{METHODS OF ANALYSIS}

The cumulative probability of conception by insemination cycle was calculated using Kaplan-Meier estimates for the two clinics separately and for four age groups. ${ }^{4}$ Proportional hazard regression analysis was used for analysing the relation between age at first

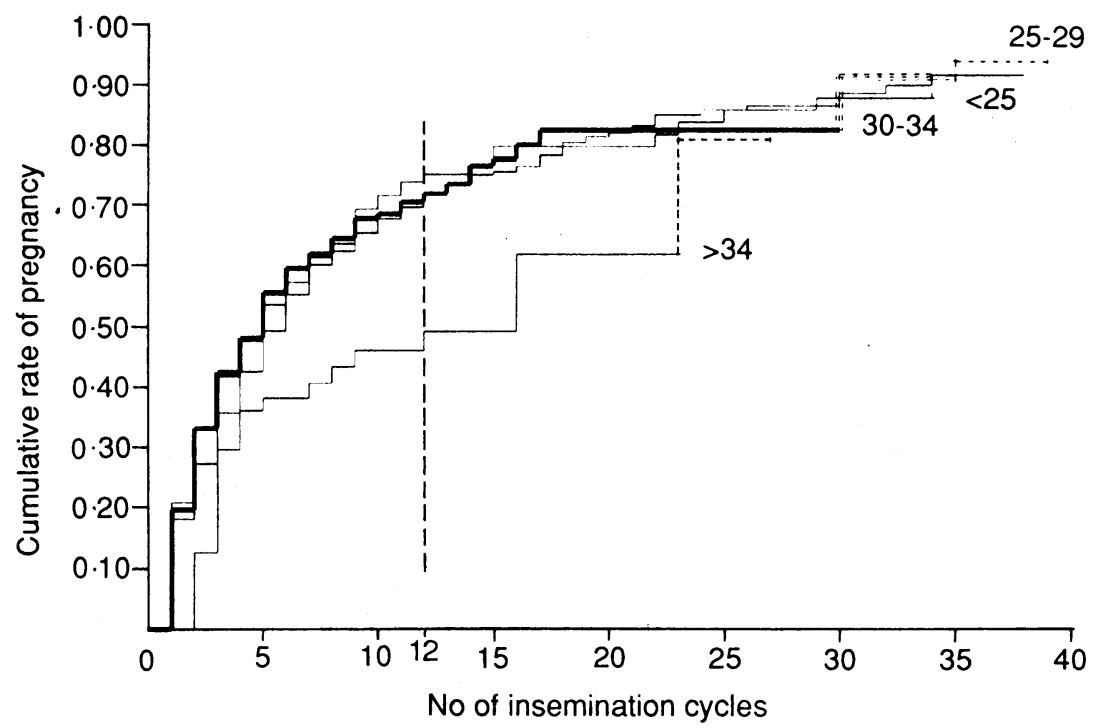

FIG 1-Cumulative rate of pregnancy according to number of insemination cycles in women of different ages (dotted line indicates that less than five women were still receiving artificial insemination)

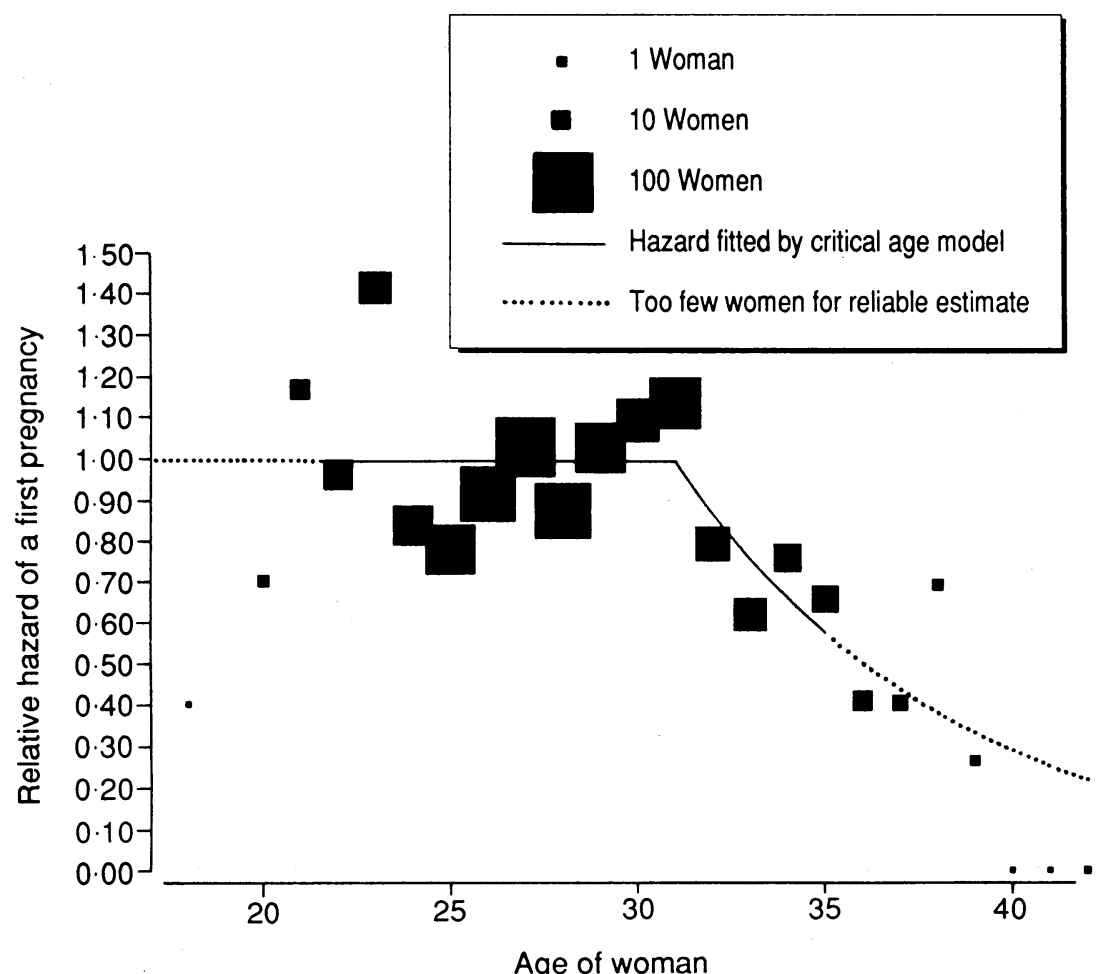

FIG 2-Pregnancy rates per cycle (hazard) according to age. Mean hazard for women aged 20-30 was scaled as 1.00. Hazards by year of age are indicated by blocks; size of block refers to number of observations. Example of use of figure-women aged 33 had a relative hazard of 0.75 indicating that a woman of that age has in each cycle $75 \%$ of the chance of a woman aged 20-30 of getting pregnant insemination and probability of conception. ${ }^{5}$ We have used the term hazard as shorthand for the more informative but longer term "pregnancy rate per cycle." We fitted models with a gradual fall of fertility (see model 1.2 in appendix) and a model that estimates a constant initial rate of pregnancy, an age at which the decrease begins (critical age), and the rate of decrease after that age (see model 1.3 in appendix). Though model 1.2 describes the biological pattern of the fall in fertility, model 1.3 would answer the question of the practising clinician-namely, at what age does the fall start? The dependency of the probability of successful pregnancy on age was analysed by logistic regression methods (see model 2.1 in appendix). ${ }^{6}$

\section{Results}

FECUNDITY

All 751 women were followed until the end of treatment; $316(71 \%)$ women in clinic A and $239(78 \%)$ women in clinic B became pregnant. Only 15 women did not report the result of their last insemination cycle. The last intake of women treated with fresh donor semen took place in 1985. None of these women were still being treated at the end of 1989. The women in clinic $B$ were on average 1.5 years older than those in clinic $A$; this difference was significant $(p<0.05)$. There was a systematic difference between clinic $A$ and clinic B in overall cumulative probability of conception. The cumulative pregnancy rates, corrected for censoring, after 12 and 24 cycles were $67 \%$ and $80 \%$ respectively for clinic $A$ and $76 \%$ and $91 \%$ respectively for clinic B.

Few women in clinic $B$ received insemination after 24 cycles; clinic A continued treatment for longer and after 35 cycles had a cumulative pregnancy rate of $90 \%$. The systematic difference in cumulative pregnancy rates between the clinics was not related to differential treatment with age by clinic. Therefore all 751 women were used for the analysis of the effects of age.

The youngest woman entering the study was 18 years old, the oldest 42 . Table I gives the age distribution of all the women. Figure 1 gives the curves of cumulative probability of conception for the four age groups. The cumulative pregnancy rates after 12 cycles were 0.75 (women aged <24), $0.72(25-29), 0.72$ $(30-34)$, and $0 \cdot 49(>34)$. The probability of conception for each age group was also calculated with the proportional hazard model (see model 1.1 in appendix). The difference in probability of conception between the oldest and the other age groups was significant (likelihood ratio test). The oldest age group had about half the hazard (pregnancy rate/cycle) of the other age groups $(95 \%$ confidence interval $0 \cdot 31$ to $0 \cdot 77)$.

In a more detailed analysis we estimated the pregnancy chances for each separate year of age (fig 2). This gave a dispersed plot as many points were based on a small number of observations. The general shape, however, corroborates the use of a model in which the probability of conception falls after a certain age. The model with a gradual fall seemed to fit the data quite well (model 1.2). At age 31 the probability of conception was $95 \%$ of the initial level, and at older ages the fall became increasingly steeper. The choice of $95 \%$, however, was quite arbitrary. For the model with the critical age (model 1.3) the fit was better than for model 1.2. Our estimation method gave a critical age of 31 years. After the age of 31 the chance of conception per cycle fell by about $12 \%$ each year of age (model 1.3 ).

To assess the goodness of fit we investigated three aspects of the regression models. Firstly, the models 1.2 and 1.3 should be adequate for describing the relation with age. Figure 2 shows that both models are valid in this respect. The critical age model performed only slightly better. Secondly, the proportional 


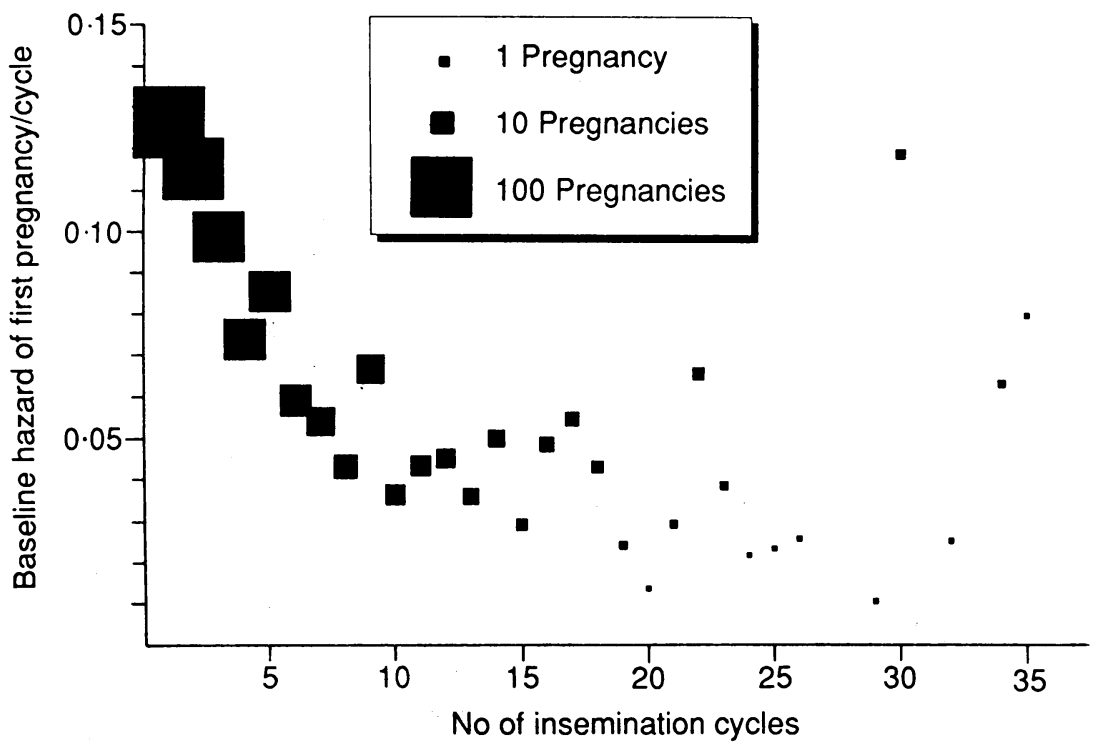

FIG 3-Baseline chance of first pregnancy (hazard) for each cycle after failures in previous cycles for women aged under 31 attending clinic $A$

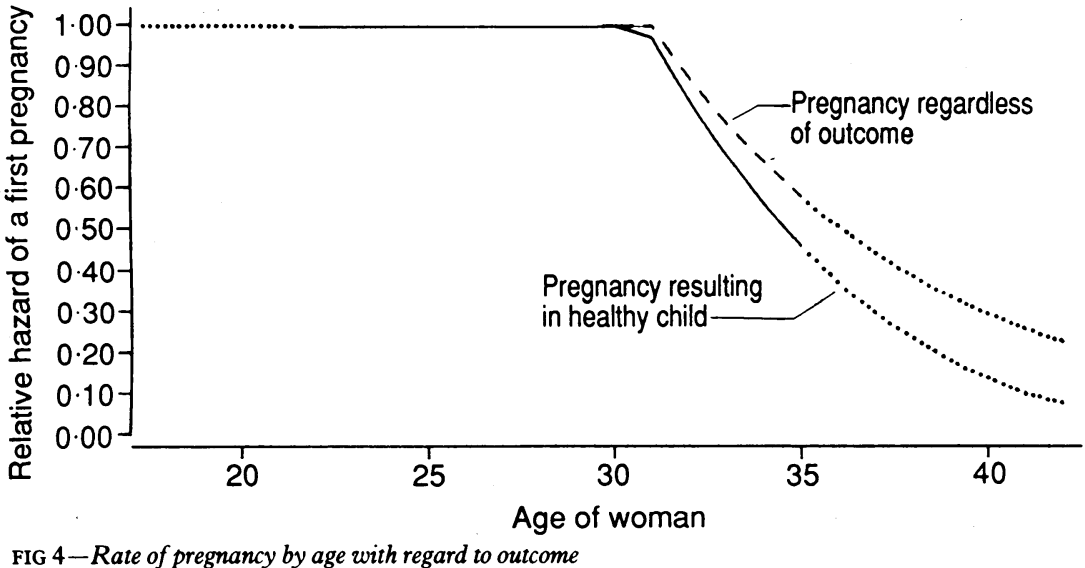

hazards should be stable for subsequent insemination cycles. We performed the analysis for the first three cycles and for later cycles separately. In both subsets the start of the fall in fertility was at age 31 . This proves the stability to be adequate. Thirdly, according to the models the difference between the clinics should be constant with age. When the data set was divided into clinics the critical age for clinic $A$ was 31 and for clinic B 33 years. This difference, however, was not significant.

Figure 3 shows how the chance of pregnancy falls in each subsequent cycle in the whole group. This fall results from the selection process by which highly fecund women tend to get pregnant earlier than less fecund women.

\section{OUTCOME OF PREGNANCY}

Of the 555 women who conceived, 532 women reported a result of pregnancy and $23(5 \%)$ did not. Table II gives the reproductive outcomes according to age group. The fall in the probability of a healthy child

TABLE II-Outcome of pregnancy according to age

\begin{tabular}{|c|c|c|c|c|c|}
\hline \multirow[b]{2}{*}{ Outcome } & \multicolumn{4}{|c|}{ No (\%) of women aged: } & \multirow[b]{2}{*}{ Total } \\
\hline & $<25$ & $25-29$ & $30-34$ & $>34$ & \\
\hline Spontaneous abortion & $9(12)$ & $30(10)$ & $20(14)$ & $6(25)$ & $65(12)$ \\
\hline Stillbirth & & $1(0 \cdot 3)$ & $2(1)$ & & $3(1)$ \\
\hline Congenital anomaly & & $1(0 \cdot 3)$ & $1(0 \cdot 7)$ & $1(4)$ & $3(1)$ \\
\hline Healthy child & $69(88)$ & $257(89)$ & $118(84)$ & $17(71)$ & $461(87)$ \\
\hline Known outcome & $78(100)$ & $289(100)$ & $141(100)$ & $24(100)$ & $532(100$ \\
\hline Unknown outcome & 8 & 9 & 5 & 1 & 23 \\
\hline Total & 86 & 298 & 146 & 25 & 555 \\
\hline
\end{tabular}

related to age was estimated by logistic regression. Analysis was done on all 555 women who conceived, 461 women reporting a healthy child and 71 women reporting adverse outcomes. The 23 women with unknown outcome were first analysed as successes, assuming that adverse outcomes would have been reported. There was a significant decrease in the chance of having a healthy child after the age of 30 (see model 2.1 in appendix). If a pregnancy occurred women aged under 30 had an $89 \%$ chance of having a healthy baby. Thereafter this chance decreased by about $3 \cdot 5 \%$ each year.

There was no significant difference between clinic A and clinic B in the probability of a baby being healthy, after correction for the difference in age between clinics (hazard ratio 1.01 ; $95 \%$ confidence interval 0.61 to 1.69 ). No significant difference was found in successful pregnancy among women who took different times to conceive (hazard ratio $1.01 /$ completed cycle; 0.96 to 1.06 ) nor between women with pregnancies that ensued after induction of ovulation and those with pregnancies occurring during spontaneous cycles (hazard ratio $1.03 ; 0.55$ to 1.94 ).

We plotted the probabilities for year of age in the same way as in figure 2 . This showed the critical age model to be adequate for modelling outcome of pregnancy. Combining the chances of pregnancy and of a pregnancy being successful, gives a curve of the falling chance of successful pregnancy with age (fig 4).

\section{Discussion}

We studied the effect of age on female fecundity and outcome of pregnancy in women receiving donor insemination. By excluding confounding variables, such as diminished sexual activity with age and various degrees of male subfertility, these women provide a better opportunity to study potentially predictive variables with regard to fecundity and outcome than do naturally selected populations. ${ }^{78}$ To prevent selection bias toward a population of lower fecundity, only women married to azoospermic husbands and who had not been treated elsewhere were admitted to the study. ${ }^{9}$

Although we cannot fully explain the difference in cumulative conception rates between clinics A and B, the difference in policy on induction of ovulation is obvious. As cycles with and without ovulation induced by clomiphene were not randomly compared we can only speculate on the adverse effect of clomiphene in women with normal ovulatory cycles. ${ }^{10}$

We added a model with a continuous fall in fecundity with age (model 1.2); we proved this to be no improvement on the critical age model (1.3). The model with an abrupt start of fall performed slightly better and, more importantly, determined when the fall in fecundity starts.

The finding of a critical age of 31 years does not seem to agree with figure 1 , which shows a significant decrease of fecundity only in women older than 34 and not in those aged 30-34. However, the good result of the $30-34$ group is caused by the fact that the pregnancy rates in women aged 30 and 31 were (possibly by chance) rather high (fig 2). We could not account for the effect of possible confounders such as smoking, alcohol, or coffee consumption because this information was not systematically available. Therefore, to be cautious we will interpret the critical age to be around 31.

The critical age around 31 for decreasing fecundity falls within the ranges found by Howe $e t$ al in women stopping contraception, ${ }^{11}$ by Schwartz and Mayaux in a population of women undergoing donor insemination, and by Menken et al in historical populations. ${ }^{12}$ The critical age did not change after correcting for the use of 


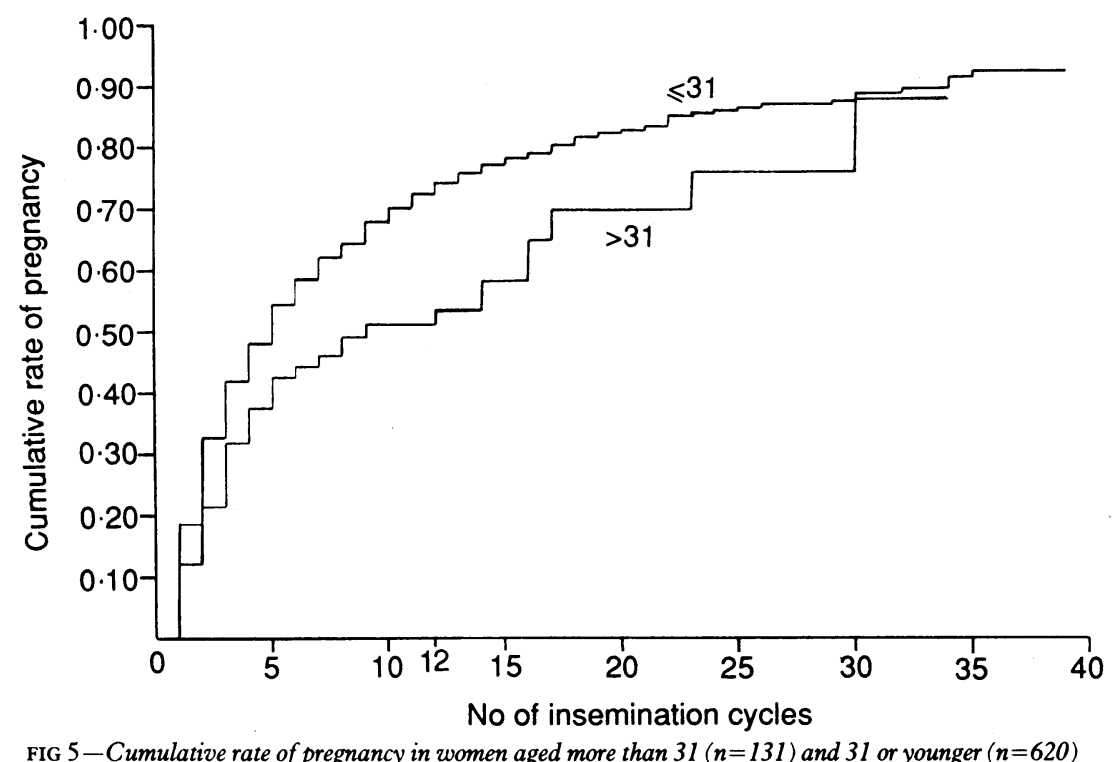

ovulation induction, nor did length of menstrual cycle affect our finding.

What are the reasons for decreasing female fertility with age? In vitro fertilisation clearly shows that the number of oocytes retrieved and the rates pregnancy obtained decrease with age. ${ }^{13}{ }^{14}$ Lower pregnancy rates may be due to a uterine factor interfering with implantation. Reports on successful oocyte donation in women over 40 , however, suggest that oocyte quality rather than uterine environment is the limiting factor in older women. ${ }^{15}$ Subtle deterioration of oocytes probably starts before the age of 35 . Anovulation, oligomenorrhoea, or cycle irregularities apparently are later reflections of the same process of deterioration.

The models that we used do not account for the fact that during a series of insemination cycles the ages of the women increase. However, the age effect was only a $1 \%$ fall per cycle after the age of 31 . Because few women received artificial insemination for a long series of cycles we would not expect including aging during the series to improve the models.

The start of the fall around age 31 means that women older than 31 will take longer to become pregnant (eventually) than would younger women. We divided the population into groups younger or equal and older than 31 (fig 5). The pattern of the curve suggests that a policy of stopping treatment in the older age group is not advisable; treatment for longer than 12 cycles seems to be worth while. After 12 cycles the pregnancy rate in the older women increased from $54 \%$ to over $75 \%$ at 24 cycles; the pregnancy rate in the younger women increased in the same period from $74 \%$ to $85 \%$. Because of the small number of women completing 24 cycles or more, however, the suggestion in our data that older women will eventually have the same pregnancy rate as younger women must be interpreted with caution.

Apart from the fecundity we also found that the chance of successful pregnancy (resulting in a healthy baby) in nulliparous women decreases after the age of 30. Classifying pregnancies in women in whom the outcome was unknown as unsuccessful did not alter this conclusion. Most fertility specialists are aware of the fall in fecundity and the chance of successful pregnancy with increasing age. When counselling women considering delaying childbearing we should know the combined effect on the likelihood of giving birth to a healthy child. We estimate that the relative chance per cycle of a 35 year old woman giving birth to a healthy baby is $50 \%$ that of women of 25 (fig 4).

Older women who do not get pregnant in the first cycle can get pregnant in one of the next cycles; as time taken to conceive was not related to outcome of pregnancy the differences between older and younger women in the cumulative probability of having a healthy child will become smaller after every subsequent cycle. Recently Berkowitz et al found that delayed childbearing poses little, if any, increased risk of adverse neonatal outcome, ${ }^{16}$ but they did not assess spontaneous abortions and chromosomal abnormalities. The positive association of unsuccessful pregnancy with age greater than 30 in our study was largely due to the contribution of spontaneous abortions. Study designs ascertaining the reproductive outcome after the gestational period when spontaneous abortions are most likely to occur will be less prone to show an age effect.

Our results are based on a cohort of women who received donor insemination. The number of women conceiving in this population is known to be lower than in a random population. ${ }^{2}$ In our analysis, however, it is the critical age and the decrease with age in the probability of pregnancy and of pregnancy being successful that are at issue. We cannot find any reason why the critical age in this population would differ from that of a population conceiving naturally. Women receiving artificial insemination still represent the most feasible way to study the age effect on female fecundity and outcome of pregnancy. The question of how long women can wait can now be answered: around the age of 31 the probability of pregnancy in nulliparous women starts to fall. Older women can get pregnant, but at a slower rate than younger women. Women over 30 face a decreasing chance of having a healthy child

We thank Dr Donna Baird (Epidemiology Branch, National Institute for Environmental and Health Sciences, Research Triangle Park, North Carolina, USA) and Dr Theo Stijnen (Department of Biostatistics, Erasmus University Medical School, Rotterdam) for their helpful suggestions. We also thank Dr Pauline Verloove-Vanhorick (Child Health Division, TNO Institute of Preventive Health Care, Leiden) and the staff of the participating clinics for their support and Mrs Ria Huls van Vliet (TNO Institute of Preventive Health Care, Leiden) for secretarial help.

\section{Appendix}

The regression models used in this paper were estimated using GLIM software. ${ }^{6}$ For non-linear models (1.2 and 1.3 ) only estimates can be calculated - that is, no standard errors. The three models for the Cox regression calculations were as follows.

\subsection{MODEL FOR AGE GROUPS}

$$
h=\lambda \mathrm{e}^{\alpha_{2} \cdot L_{2}+\alpha_{3} \cdot L_{3}+\alpha_{4} \cdot L_{4}+x \cdot K}
$$

Where:

$\mathrm{h}=$ Hazard of pregnancy in cycle $\mathrm{t}-$ that is, the probability of pregnancy in cycle $t$ assuming that no pregnancy has occurred until then.

$\lambda=$ Baseline hazard in cycle $\mathbf{t}$ (not modelled). The baseline group consists of women from age group 1 and clinic A. $\alpha_{\mathrm{i}}=$ Parameter for the difference between the hazards for age group $i$ and age group 1.

$\mathrm{L}_{\mathrm{i}}=$ Dummy variable, which takes the value 1 when the woman belongs to age group $i$ and zero otherwise. $x=$ Parameter for the difference between the two clinics.

$\mathrm{K}=$ Dummy variable, which takes the value 1 when the woman is treated by clinic $B$ and zero otherwise.

The age groups are $<25(1), 25-29(2), 30-34(3) \geqslant 35(4)$. The baseline hazard $(\lambda)$ was found to fall with increasing number of cycle. It reflects a selection effect: women with high fecundity get pregnant leaving after some cycles a higher proportion of women with average low fecundity to remain in the population. Parameter estimates are $\alpha_{2}=-0.09$, $\alpha_{3}=-0.07, \alpha_{4}=-0.71$, and $x=0.28$.

When the number of age groups is equal to the number of different ages in the study population this model estimates the hazards as indicated by the blocks in figure 2 . 


$$
h=\lambda \mathrm{e}^{B \cdot l^{\mathrm{n}}+x \cdot \mathrm{K}}
$$

Where:

$\beta=$ Parameter for the strength of the effect of age.

$\pi=$ Parameter for the abruptness of the start of fall.

$\lambda=$ Age (now a continuous explanatory variable).

This model fits a smooth curve that is almost constant at first and then starts to fall with an abruptness depending on the value of $\pi$. The best estimate for $\pi$ was 13.1 ; addition of lower order polynomials did not improve the fit, which means that a rise in fecundity of younger women is not supported by our data. The log likelihood was 3493.8 .

1.3 CRITICAL AGE MODEL

$$
\begin{aligned}
& \mathrm{h}=\lambda \mathrm{e}^{\beta \cdot \mathrm{m}+x \cdot \mathrm{K}} \\
& \mathrm{m}=(\mathrm{l}-\gamma \mid \mathbf{l}>\gamma)
\end{aligned}
$$

Where:

$\lambda=$ Critical age (age where the fall starts)

$\beta=$ Rate of fall after the critical age.

$\mathrm{m}=$ Number of years older than critical age, or zero if younger.

Only discrete values of the critical age were investigated. The value with the maximum likelihood was selected. Therefore standard errors could not be calculated.

Figure 3 shows the baseline hazards $(\lambda)$. The relative hazards $\left(\mathrm{e}^{\beta \cdot \mathrm{m}+x \cdot \mathrm{K}}\right)$ are indicated by the line in figure 2 . The estimates were $\gamma=31, \beta=-0 \cdot 136$, and $x=0.272$. The log likelihood was 3491.9 with the same degrees of freedom as model 1.2. The estimated hazard of a certain woman in a certain cycle (h) can be calculated by multiplication of the baseline hazard $(\lambda)$, depending on the number of the cycle and the relative hazard $\left(\mathrm{e}^{\beta \cdot \mathrm{m}+x \cdot \mathrm{K}}\right)$ depending on the age and clinic.

We realise that the fact that our population consisted of a mixture of fertile and infertile women is theoretically incompatible with the use of the Cox regression model. ${ }^{17}$ The mixed character of the population should lead to a constant shift in the proportional hazards between young and old women with time (insemination cycle). However, modelling interaction of the parameters with time (that is, assuming $\beta$ and $\gamma$ are different in a first and second period of time) does not lead to a significantly better fit. We therefore conclude that the theoretical incompatibility does not cause problems in this particular analysis.
2.1 LOGISTIC MODEL FOR PROBABILITY OF SUCCESSFUL PREGNANCY

$$
\mathrm{p}=\frac{\mathrm{e}^{\mathrm{a}+\beta \cdot \mathrm{m}+x \cdot \mathrm{K}}}{1+\mathrm{e}^{\mathrm{a}+\beta \cdot \mathrm{m}+x \cdot \mathrm{K}}}
$$

Where $p$ is the probability of successful pregnancy. The other symbols have the same meaning as in model 1.3. The estimator for difference between clinics $(x)$ was not significant. The parameters of the model without $x$ were $\alpha=2.13$, $\beta=-0 \cdot 25$, and $\gamma=30$.

1 Schwartz D, Mayaux MJ. Female fecundity as a function of age. $N$ Engl $\mathcal{F}$ Med 1982;306:404-6.

2 Bongaarts J. Infertility after age 30: a false alarm. Fam Plann Perspect 1982;14:75-8.

3 Stein ZA. A woman's age: childbearing and child rearing. Am $\mathcal{f}$ Epidemiol 1985;121:327-43.

4 Kaplan EK, Meier P. Non-parametric estimation from incomplete observations. Fournal of the American Statistics Association 1958;53:457-81.

5 Cox DR. Regression models and life tables. Foumal of the Royal Statistical Society 1972;34(series B): 187-202.

6 Aitkin MD, Anderson AO. Statistical modelling in GLIM. Oxford: Clarendon Press, 1989.

7 Spira A. The decline of fecundity with age. Maturitas 1988;suppl 1:15-22.

8 Van Noord-Zaadstra BM, Karbaat J, te Velde ER, Habbema JDF, van der Maas PJ. The study of risk habits in reproductive and perinatal epidemiologic research: the use of a donor inseminated population of women. Paediatr Perinat Epidemiol 1989;3:11-8.

9 Emperaire JC, Gauzere-Soumireu E, Audebert AJM. Female fertility and donor insemination. Fertil Steril 1982;37:90-3.

10 Yoshimara Y, Hosoi Y, Atlas SJ, Wallach EE. Effect of clomiphene citrate on in vitro ovulated ova. Fertil Steril 1986;45:800-4.

11 Howe G, Westhoff C, Vessey M, Yeates D. Effects of age, cigarette smoking, and other factors on fertility: findings in a large prospective study. $B M \mathcal{F}$ 1985;290:1697-1700.

12 Menken J, Trussell J, Larsen U. Age and infertility. Science 1986;233: 1389-95.

13 Harrison KL, Breen TM, Hennesy JF, et al. Patient age and success in a human IVF programme. Aust $N Z$ f Obstet Gynaecol 1989;29:326-8.

14 Medical Research International Society for Assisted Reproductive Technology, the American Fertility Society. In vitro fertilization-embryo transfer (IVF-ET) in the United States: 1989 results from the IVF-ET registry. Fertil Steril 1991;55:14-23.

15 Sauer MV, Paulson RJ, Lobo RA. A preliminary report on oocyte donation extending reproductive potential to women over 40. $N$ Engl f Med 1990;323:1-60.

16 Berkowitz GS, Skovron ML, Lapinski RH, Berkowitz RL. Delayed childbearing and the outcome of pregnancy. $N$ Engl f Med 1990;322:659-64.

17 Lamb EJ, Hagen N, Pauker SG. The mean interval to conception: a measure of utility for the analysis of decisions involving fertility. Am $\mathcal{F}$ Obstet Gynecol 1989;160:1470-8.

(Accepted 18 April 1991)
Office of Population Censuses and Surveys, London WC2B 6JP Anna McCormick, FFPHM, senior medical statistician

\section{Unrecognised HIV related deaths}

\author{
Anna McCormick
}

\section{Abstract}

Objectives-To establish whether follow up of deaths from selected HIV related causes could increase the number of cases of HIV infection reported to the Public Health Laboratory Service Communicable Disease Surveillance Centre (CDSC), and to estimate the proportion of deaths among HIV positive men that occurred in men who were not known to be HIV positive at the time of death by the person who signed the death certificate.

Design-Follow up of draft death entries received by the Office of Population Censuses and Surveys on which one of 11 medical or external causes likely to be related to HIV was stated; letters were sent to the people who signed the certificates. The respondents were invited to report men known to have been HIV positive who were not already on the CDSC register.

Setting-England and Wales.

Subjects-Men aged 15-54 who died in February 1989 to July 1989 with one of the 11 selected HIV related diseases as cause of death on their death certificates.

Main outcome measures-Number of men reported to the CDSC as a result of this follow up; estimate of excess deaths due to an HIV related cause; estimate of the proportion of excess deaths that occurred in those who were not known to be HIV positive at the time of death.

Results-Replies were received for 473 deaths (86\%). Forty were for men known to have been HIV positive, 31 of whom had been reported to CDSC by the time they died; six were subsequently reported. The respondent did not know that the deceased was HIV positive for $20(35 \%)$ of the 57 excess deaths in men for whom one of the medical causes was stated and $41(93 \%)$ of the 44 excess deaths in men for whom one of the external causes was stated.

Conclusion-Follow up of death registrations is not an efficient way of increasing the number of cases of HIV infection reported to CDSC. Between $35 \%$ and $60 \%$ of HIV positive people for whom certain causes are stated may be dying without HIV positivity having been diagnosed. There may be implications for those caring for people with these conditions and those who carry out postmortem examinations.

\section{Introduction}

On p 1375 I report that mortality from 95 selected causes increased by $25 \%$ between 1984 and 1989 among single men aged 15-54 and there is evidence that 